\title{
Zeit- und Festrechnung 1959
}

Das Jahr 1959 entspricht dem

Jahr 66/2 der Julianischen Periode und dem

Jahr 7467-7468 der Byzantinischen Ära.

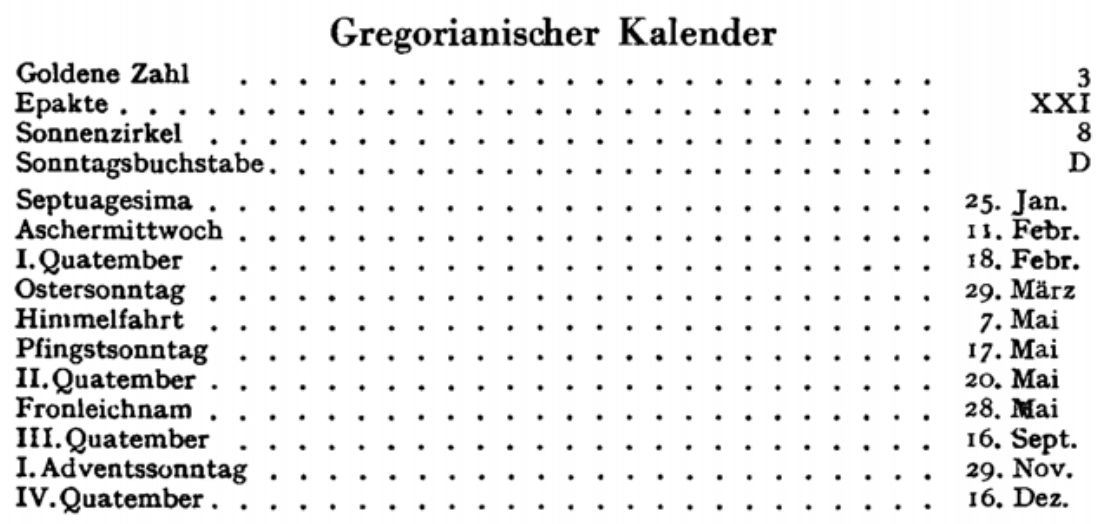

\section{Dimensionen der Erde}

a) Nach Bessel (1841)

Große Halbachse $a=6377397.155 \mathrm{~m} \quad \log a=6.8046434637$

Kleine Halbachse $b=6356078.963 \mathrm{~m} \quad \log b=6.8031892839$

Abplattung $a=1: 299.1528129 \quad \log a=7.5241069092-10$

Meridianquadrant $=10000855.76 \mathrm{~m}$

Die Maßeinheit der Lănge ist das legale Meter.

b) Nach Ha y ford (1909)

identisch mit Internationalem Ellipsoid (1924)

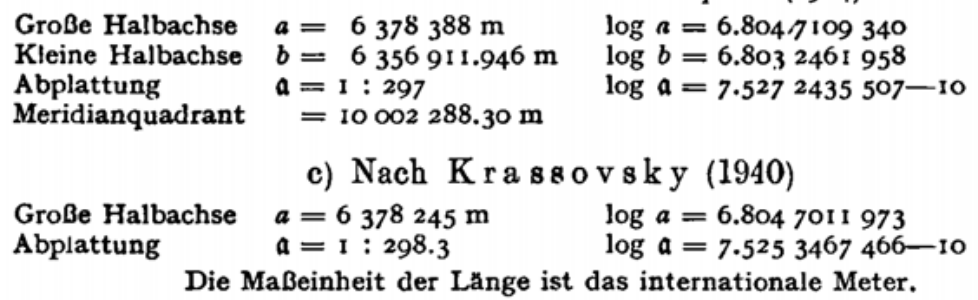

E.in internationales Meter $=0.9999866$ legales Meter.

Will man die Lange einer in legalen Metern gemessenen Strecke in internationalen Metern angebsn, so hat man die Anzahl der legalen Meter mit 1.000 0134 zu multiplizieren.

Normalwert für die Schwerebeschleunigung im Meeresniveau :

$\gamma_{0}=978.030\left(\mathrm{t}+0.005302 \cdot \sin ^{2} \mathrm{p}-0.000007 \cdot \sin ^{2} 2 \mathrm{p}\right) \mathrm{cm} \cdot \mathrm{sec}^{-2}$. (Helmert 1901)

$\gamma_{0}=978.0470\left(1+0.005288_{4} \cdot \sin ^{2}\right.$ ? $\left.-0.0000059 \cdot \sin ^{2} 2 p\right) \mathrm{cm} . \mathrm{sec}^{-2}$. (Cassinis 1930)

Masse der Erde: $5.974 \cdot 10^{27} \mathrm{~g}$

Masse der Sonne: $1.983 \cdot 10^{33} \mathrm{~g}$

Radius der Sonne: $695300 \mathrm{~km}$

Mittlere Entfernung Erde-Sonne: $149504210 \mathrm{~km}$

Lichtzeit für die mittlere Entfernung Erde-Sonne: $498^{\text {S.72 }}$ (mit Lichtgeschwindigkeit $299774 \mathrm{~km} / \mathrm{sec}$.) 